\title{
Glove single-port laparoscopy-assisted transanal total mesorectal excision for low rectal cancer: a preliminary report
}

\author{
Wanglin $\mathrm{Li}^{1 *+}$, Boye Dong ${ }^{3+}$, Baifu Peng ${ }^{2 \dagger}$, Jiabao $\mathrm{Lu}^{2}$, Zixin $\mathrm{Wu}^{1}$, Guanwei $\mathrm{Li}^{1}$ and Jie Cao ${ }^{{ }^{*}}$
}

\begin{abstract}
Purpose: Glove single-port laparoscopy-assisted transanal total mesorectal excision (TaTME) has been successfully carried out in our medical center. The purpose of this study is to evaluate the feasibility of this emerging operation.

Methods: This technique was performed by self-made glove single-port laparoscopic platform to radically resect low rectal cancer. Short-term postoperative results, including complications, length of hospital stay, and follow-up results were collected and analyzed statistically.

Results: There are five consecutive patients (three males, two females) who underwent this surgery and included in this study. The mean distance from the tumor to the anal verge was $4.8 \mathrm{~cm}$ (range 4.0-6.0). The surgery was completed in all cases, and the rectal tumor was removed successfully without conversion; circumferential margins of all the excised specimens were negative. The mean time of operation was $338.00 \mathrm{~min}$ (range 280-400). The average number of lymph node dissection was 12.20. The average postoperative hospital stay was 8.60 days. During the follow-up (14.80 \pm 1.92 months), all preventive ileostomies were successfully closed in about 3 months after the surgery, all patients had satisfactory anal function, and no tumor recurrence was found.

Conclusion: Glove single-port laparoscopy-assisted TaTME has a significant effect in specific patients with low rectal cancer, with rapid recovery and high safety. Prospective randomized studies involving more case counts and longterm follow-up results, especially oncologic outcomes, are needed to validate this technique.
\end{abstract}

Keywords: Glove port, Single-port laparoscopic surgery, Transanal total mesorectal excision, Rectal cancer

\section{Introduction}

In recent decades, with the application and maturity of laparoscopy even robotics, minimally invasive surgery has developed rapidly in the field of colorectal cancer, and many new technologies have come into being. In recent years, the concept of natural orifice transluminal surgery (NOTES) has attracted the attention of surgeons. The "incision-free" concept of NOTES combined with the operational skills of laparoscopy shows perfect minimally invasive effect, as well as good safety and operability. Compared to conventional laparoscopic surgery, NOTES provides many potential advantages for

\footnotetext{
*Correspondence: 421255910@qq.com; czhongt@126.com

${ }^{\dagger}$ Author Wanglin Li, Boye Dong, Baifu Peng contributed equally.

'Department of Colorectal Surgery, Guangzhou First People's Hospital,

School of Medicine, South China University of Technology, No.1 Panfu Road,

Guangzhou 510180, Guangdong, China

Full list of author information is available at the end of the article
}

selected rectal cancer patients, such as avoiding transabdominal incisions and their related complications [1].

Transanal total mesorectal excision (TaTME) is an emerging NOTES surgery. Previously, most of the reported TaTME cases were performed through traditional multi-port laparoscopic surgery (MPLS). However, as a developed technique, single-port laparoscopic surgery (SPLS)-assisted TaTME was reported relatively fewer, though it is becoming more and more noticeable in recent years [2-4]. With great interest in SPLS, we successfully performed TaTME with self-made glove single-port laparoscopic platform in our medical center. According to the statistics, the expense of this self-made platform is about 2500 dollars lower than that of the single-item platform, such as GelPoint platform. Now, we introduce the preliminary outcomes on patients who underwent TaTME using this self-made glove single-

(c) The Author(s). 2019 Open Access This article is distributed under the terms of the Creative Commons Attribution 4.0 International License (http://creativecommons.org/licenses/by/4.0/), which permits unrestricted use, distribution, and 
port laparoscopic platform, including the surgical platform and operation details, short-term outcomes, and follow-up results.

\section{Materials and methods}

This study started in January 2015. Specimens were assessed according to our protocol. Informed consent was obtained after detailed explanations of the benefits, possible complications or risks, and alternatives of the operation.

\section{Patient}

Patients with histologically proven T1-T3 low rectal adenocarcinoma were included in the study. All tumors were in a distance less than $6 \mathrm{~cm}$ from the anal verge. Patients with local recurrence and distant metastases, locally advanced tumors (cT4 stage), acute intestinal obstruction, poor anal function, history of ulcerative colitis or Crohn's disease, and familial adenomatous polyposis were excluded. All patients underwent colonoscopy, lower abdominal magnetic resonance imaging (MRI), thoracoabdominal computed tomography (CT) scan, and sphincter manometry for adequate preoperative evaluation. According to the guidelines for the diagnosis and treatment of colorectal cancer, patients with clinically positive lymph node received neoadjuvant chemoradiotherapy.

\section{Surgical technique}

Patients who underwent neoadjuvant therapy will wait 8 to 12 weeks since completing radiotherapy before surgery. All patients received mechanical bowel preparation (MBP) combined with oral antibiotics for preoperative bowel preparation. MBP was done using oral polyethylene glycol electrolyte powder or cleaning enema. Oral antibiotics commonly used are ciprofloxacin and metronidazole.

The anesthesia method was general anesthesia with endotracheal intubation. After successful anesthesia, the lithotomy position was taken, and the head was lowered, the lower limbs were raised and outspread, fully exposing the anus. To achieve fast recovery after surgery, the stomach tube was not inserted if it was not necessary, and the urinary catheter was pulled out within $24 \mathrm{~h}$ after surgery. A drainage tube was placed to drain the pelvic cavity accumulating liquid.

Key surgical steps were as follows: Firstly, we rinsed the operative region including the rectum lumen with sterile solution and fully exposed the rectum with an anal retractor, then confirmed the tumor lesion location and accurately decided the level of incision in the lumen (Fig. 1a). Secondly, we used purse-string suture to close the rectum tightly, then performed a full-thickness circumferential dissection (partial intersphincteric dissection was needed for ultra-low cancer) (Fig. 1b). Thirdly, the self-made glove single-port platform was constructed and inserted. The platform was structured mainly using surgical gloves and wound protectors. The surgical glove fingertips were cut, and then, trocars (one $10 \mathrm{~mm}$, one or two $5 \mathrm{~mm}$ ) were inserted through the tip-holes and secured. Then, the operating instruments and endoscope lens were inserted through the trocars,

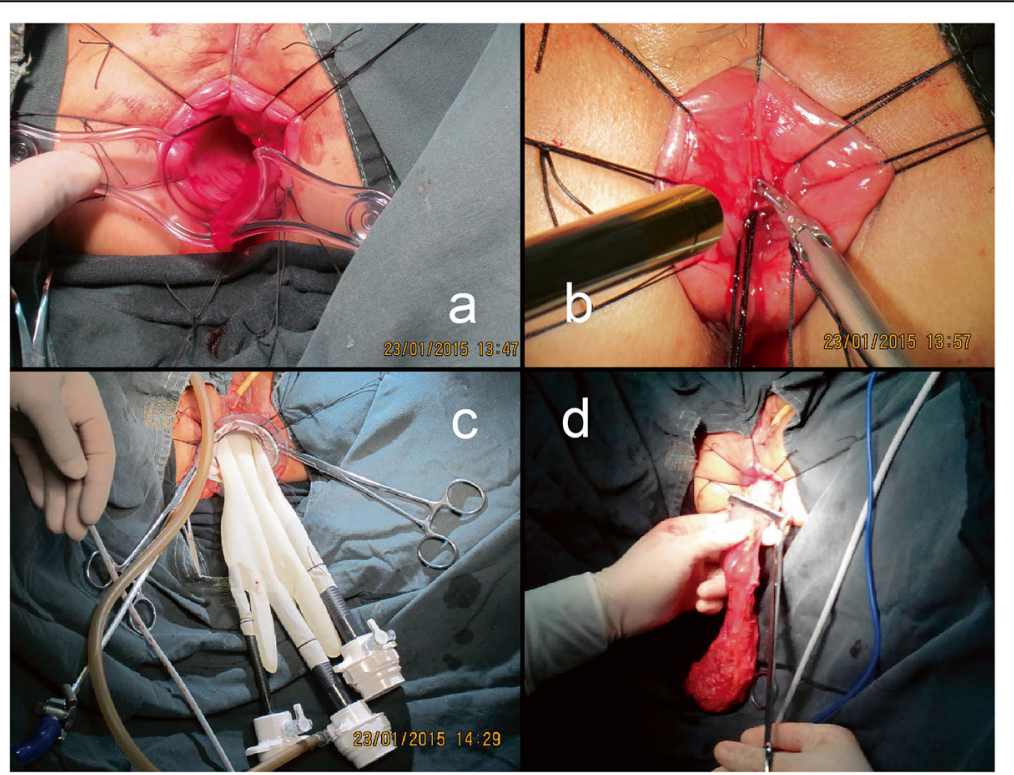

Fig. 1 Surgical approach. a The rectum was fully exposed with an anal retractor, then the tumor lesion location was confirmed and the level of incision in the lumen was accurately decided. $\mathbf{b}$ The rectal lumen was tightly occluded, and a full-thickness circumferential dissection was performed. c The glove single-port platform was constructed by the surgical gloves and trocars. $\mathbf{d}$ The specimen was extracted through the anus 
and the instruments were fixed on the fingertip holes of the glove with stitches. In this process, attention should be paid to avoid the "chopstick effect" of operating instruments and to ensure that trocars are well fixed with the fingertip holes of the glove to avoid air leakage. Since the anal canal anatomy would not be suitable for setting a wound protector, an anal speculum was used instead to construct the glove anal single-port laparoscopic platform. The anal speculum was fixed on the perianal skin of the patient, and then, the glove operating platform was securely fixed to the anal speculum with sutures. Then, the glove single-port platform was finished and the pneumo-pelvis was established (Fig. 1c). Dissection was performed first on the posterior side, then the lateral side, paying attention to the protection of the ureter and pelvic plexus. Finally, the anterior side of the rectum was dissected along the Denonvilliers' fascia. The abdominal cavity was accessed by incising anteriorly or through the right side.

In the abdominal approach, the glove single-port platform was placed at the future ileostomy site. After abdominal exploration, if abdominal dissection was difficult, an additional umbilical port was added, and then adopted the medial-to-lateral approach: firstly, we used the ultrasonic scalpel and absorbable clips to separate, skeletonize, ligate, and divide the submesenteric blood vessels, as well as dissection of the regional lymph nodes. And then, we dissected the descending colon, sigmoid colon, and the upper rectum until the tumor was in free continuity with the previous transanal operation.

Finally, we pulled the specimen out through the anus (Fig. 1d). Then, we used the stapler to perform an endto-end coloanal anastomosis and created a protective ileostomy to ensure better healing of the anastomosis. The rubber tube was routinely left for $3-5$ days as a pelvic drainage.

\section{Results}

From January to June 2015, there are five consecutive patients (including three males and two females) who were included in this study. The average age was 59.4 years (range 43-68). Body mass index (BMI) ranged from 19.5 to 25.2. All lesions were proved to be adenocarcinoma located in low rectum by taking pre-operative biopsies, with mean distance from the anal verge of 4.8 cm (range 4-6). The demographic characteristics, operative information, pathologic outcomes, and follow-up data are summarized in Table 1.

All cases underwent creation of protective ileostomies without conversions to open operation. The average operative time was $338 \mathrm{~min}$ (range 280-400). The mean estimated blood loss was $76 \mathrm{ml}$ (range 50-150). In all specimens, the mesenteric fascia remained intact, and no tumor invasion was found at the distal and peripheral margins. The average number of lymph node dissection was 12.20 (range 11-13).

In terms of rehabilitation, the mean time for postoperative passing flatus was 3 days (range 2-4), indicating intestinal movement begins to recover; length of hospital stay ranged from 7 to 10 days with an average of 8.6 days. One patient experienced stoma prolapse slightly at 2 months after surgery. The patient was treated conservatively and made a fast recovery. Follow-up (14.8 \pm 1.92 months, range 12-17) results showed that all ileostomies had been successfully closed; no tumor recurrence or fecal incontinence was found in the patients.

\section{Discussion}

Developments in surgical techniques within each passing day have had improved patient outcomes, especially in the field of colorectal cancer surgery. To chase shorter wounds and faster recovery, new techniques such as SPLS have emerged [2, 5, 6]. Though SPLS have been shown to be feasible in colon cancer [7], SPLS for rectal cancer, especially for distal rectal cancer, is relatively more difficult and challenging $[5,7,8]$.

The recently developed TaTME technique embodies the concept of NOTES [9] and may be a superior approach for rectal cancer $[2,10]$. TaTME could resect the lesions completely and ensure negative circumferential margin, while it extracts the specimen through the anus and may avoid the vaginal or larger abdominal incisions [11].

According to the transanal endoscopic platform, TaTME can be classified as transanal endoscopic microsurgery-TME (TEM-TME) using TEM platform and transanal minimally invasive surgery-TME (TAMISTME) using TAMIS platform. Early on, at the time of TaTME implementation, the more common approach was TEM-TME [12]. In 2010, laparoscopy-assisted TEM-TME was reported by Sylla et al. and came out with no post-operative complications [11]. Along with the implementation and development of intraluminal minimally invasive surgery using the TAMIS platform, TAMIS was developed to achieve TaTME operation. Surgeons have now preferentially adopted the disposable multi-channels single-port platform for TAMIS [13, 14]. TaTME permits a clear and magnified filed to get access to the confined distal rectum from below [15]. Hence, it may reduce the difficulty of the operation and avoid some difficult situations encountered by conventional laparoscopic surgery, such as the use of stapling multiple times across the rectum, which increases the likelihood of anastomotic leak and involved distal resection margin [16].

However, when performing pure TaTME, it is challenging to divide the inferior mesenteric vessels and achieve colonic mobilization [12]. Many surgeons still tend to use the conventional MPLS as assistance because of the consideration of its flexibility and security. Recently, 
Table 1 Outcomes of glove single-port laparoscopy-assisted transanal total mesorectal excision

\begin{tabular}{|c|c|c|c|c|c|c|}
\hline & Patient\#1 & Patient\#2 & Patient\#3 & Patient\#4 & Patient\#5 & Mean \pm SD \\
\hline Age (years) & 43 & 58 & 68 & 62 & 66 & $59.4 \pm 9.94$ \\
\hline Gender & Female & Male & Male & Female & Male & - \\
\hline Body mass index $\left(\mathrm{kg} / \mathrm{m}^{2}\right)$ & 19.5 & 23.5 & 23.2 & 25.2 & 24.6 & $23.2 \pm 2.22$ \\
\hline ASA score & 1 & 1 & 2 & 2 & 1 & - \\
\hline Underlying disease & No & No & $\mathrm{HBP}$ & No & No & - \\
\hline Previous abdominal operation & No & No & No & No & No & - \\
\hline Distance from anal verge $(\mathrm{cm})$ & 5.0 & 6.0 & 4.0 & 5.0 & 4.0 & $4.8 \pm 0.84$ \\
\hline Diameter of tumor (cm) & 1.5 & 3.0 & 2.0 & 2.5 & 2.0 & $2.2 \pm 0.57$ \\
\hline Tumor position & Left lateral & Anterior & Posterior & Anterior & Anterior & - \\
\hline Neoadjuvant therapy & Yes & No & No & No & No & - \\
\hline Operative time (min) & 280 & 360 & 400 & 310 & 340 & $338.0 \pm 46.04$ \\
\hline Estimated blood loss (ml) & 50 & 150 & 50 & 80 & 50 & $76.0 \pm 43.46$ \\
\hline Length of specimen (cm) & 9.0 & 10.0 & 8.0 & 9.0 & 10.0 & $9.2 \pm 0.84$ \\
\hline Lymph nodes harvested & 12 & 13 & 11 & 12 & 13 & $12.2 \pm 0.84$ \\
\hline (y)TNM stage & yT1NOMO & T3N1M0 & T1NOMO & T2NOMO & T2N1M0 & - \\
\hline Circumferential margin & Negative & Negative & Negative & Negative & Negative & - \\
\hline Bowel movement (days) & 3 & 2 & 3 & 4 & 3 & $3.0 \pm 0.71$ \\
\hline LOS (days) & 8 & 7 & 9 & 10 & 9 & $8.6 \pm 1.14$ \\
\hline Conversion & No & No & No & No & No & - \\
\hline Reoperation & No & No & No & No & No & - \\
\hline Complications & No & Stoma prolapse & No & No & No & - \\
\hline 30-day readmission & No & No & No & No & No & - \\
\hline Follow-up (months) & 17.0 & 16.0 & 14.0 & 15.0 & 12.0 & $14.8 \pm 1.92$ \\
\hline
\end{tabular}

ASA American Society of Anesthesiologists, HBP high blood pressure, (y) TNM stage for patients that received neoadjuvant chemoradiotherapy, LOS length of hospital stay

several groups have reported large case series of SPLSTaTME $[2,3,6]$ and pointed out that SPLS-TaTME approach might be easier to operate than the conventional MPLS approach. Reports of the SPLS-assisted technique also described using one or more additional trocars on a single-port basis for difficult dissection, such as a high splenic flexure $[17,18]$. In the present study, we added one trocar in the umbilical position in one case. Since the umbilicus is the congenital scar, the post-operation scar at the umbilicus will still keep good cosmesis. We believe that it is a good choice to use this position if an additional port is required.

Because of the high equipment costs, low-income patients may hardly afford commercially available SILSspecific instruments and ports, such as GelPoint (Applied Medical Company). The glove port described in this study was constructed economically with a surgical glove, an anal speculum, and some trocars, saving a lot of equipment and platform costs.

To shorten the operative time, two teams could perform the first part and the second part of the presented surgery respectively at the same time. Due to the limitations of personnel and experience, we did not adopt this respective way during our study.

The major limitation of this study is the small sample size and selection bias. All patients were selected by the operating surgeon. Because of the short follow-up period, we could only draw limited conclusions about the oncological and short-term functional outcomes. The advantages of TaTME, especially for low rectal tumors or in the narrow male pelvis, demand this technique which continues to be refined and investigated.

\section{Conclusions}

This study indicated that glove single-port laparoscopyassisted TaTME has a significant effect in specific patients with low rectal cancer, with rapid recovery and high safety. Although the results showed that the shortterm outcomes of this new technique were satisfactory, the sample size of this study was small; thus, prospective randomized studies involving more case counts and long-term follow-up results, especially oncologic and functional outcomes, are needed to validate this technique. 


\section{Acknowledgements}

The authors have no conflicts of interest or financial ties relevant to the present study. This work was supported by grants from Natural Science Foundation of Guangdong (2015A030313729) and Guangzhou Science Technology and Innovation Commission (201804010073).

\section{Study performed institution}

Department of Colorectal Surgery, Guangzhou First People's Hospital, School of Medicine, South China University of Technology

\section{Authors' contributions}

WLL and JC designed the study. BYD statistically analyzed the data and drafted the manuscript. BFP was responsible for collecting patient information. JBL, ZXW, and GWL made the charts and consulted the literature. All authors read and approved the final manuscript.

\section{Funding}

The study was funded by the Natural Science Foundation of Guangdong (2015A030313729) and Guangzhou Science Technology and Innovation Commission (201804010073)

\section{Availability of data and materials}

All data generated or analyzed during this study are included in this published article and its supplementary information files.

\section{Ethics approval and consent to participate}

The study was approved by the Guangzhou First People's Hospital ethics committee. All participants were informed of the study and signed a consent form to participate.

\section{Consent for publication}

Written informed consent for publication was obtained.

\section{Competing interests}

The authors declare that they have no competing interests.

\section{Author details}

'Department of Colorectal Surgery, Guangzhou First People's Hospital, School of Medicine, South China University of Technology, No.1 Panfu Road, Guangzhou 510180, Guangdong, China. 'Department of Colorectal Surgery, Guangzhou First People's Hospital, Guangzhou Medical University, School of Medicine, Guangzhou, Guangdong, China. ${ }^{3}$ Department of Gastrointestinal Surgery, Shunde Hospital of Southern Medical University, Shunde, Foshan, China.

Received: 30 May 2019 Accepted: 6 November 2019

Published online: 30 November 2019

\section{References}

1. Kuhry E, SchwenkW GR, et al. Long-term outcome of laparoscopic surgery for colorectal cancer: a Cochrane systematic review of randomized controlled trials. Cancer Treat Rev. 2008;34:498-504.

2. Dumont F, Goere D, Honore C, et al. Transanal endoscopic total mesorectal excision combined with single-port laparoscopy. Dis Colon Rectum. 2012;55: 996-1001.

3. Velthuis $\mathrm{S}$, van den Boezem $\mathrm{PB}$, van der Peet $\mathrm{DL}$, et al. Feasibility study of transanal total mesorectal excision. Br J Surg. 2013;100:828-31.

4. Tuech JJ, Bridoux V, Kianifard B, et al. Natural orifice total mesorectal excision using transanal port and laparoscopic assistance. Eur J Surg. 2011; 37:334-5.

5. Hamabe A, Takemasa I, Uemura M, et al. Feasibility of single-port laparoscopic surgery for sigmoid colon and rectal cancers and preoperative assessment of operative difficulty. J Gastrointest Surg. 2014;18:977-85.

6. Tuech JJ, Karoui M, Lelong B, et al. A step toward NOTES total mesorectal excision for rectal cancer: endoscopic transanal proctectomy. Ann Surg. 2015:261:228-33.

7. Jung KU, Yun SH, Cho YB, et al. Single incision and reduced port laparoscopic low anterior resection for rectal cancer: initial experience in 96 cases. ANZ J Surg. 2016;86:403-7.

8. $\quad$ Sirikurnpiboon S, Jivapaisarnpong P. Single-access laparoscopic rectal surgery is technically feasible. Minim Invasive Surg. 2013;687134.
9. Chen WH, Luo SL, Kang L. Transanal total mesorectal excision: will it be a valid alternative in rectal cancer surgery? Ann Surg. 2015. https://doi.org/10. 1097/SLA.0000000000001108

10. Sourrouille I, Dumont F, Goere D, et al. Resection of rectal cancer via an abdominal single-port access: short-term results and comparison with standard laparoscopy. Dis Colon Rectum. 2013;56:1203-10.

11. Sylla P, Rattner DW, Delgado S, et al. NOTES transanal rectal cancer resection using transanal endoscopic microsurgery and laparoscopic assistance. Surg Endosc. 2010;24:1205-10.

12. Whiteford MH, Denk PM, Swanstrom LL. Feasibility of radical sigmoid colectomy performed as natural orifice transluminal endoscopic surgery (NOTES) using transanal endoscopic microsurgery. Surg Endosc. 2007;21: 1870-4.

13. Martin-Perez B, Andrade-Ribeiro GD, Hunter L, et al. A systematic review of transanal minimally invasive surgery (TAMIS) from 2010 to 2013. Tech Coloproctol. 2014;18:775-88

14. Chen WH, Kang L, Luo SL, et al. Transanal total mesorectal excision assisted by single-port laparoscopic surgery for low rectal cancer. Tech Coloproctol. 2015;19:527-34

15. Atallah $\mathrm{S}$, Martin-Perez B, Albert M, et al. Transanal minimally invasive surgery for total mesorectal excision (TAMIS-TME): results and experience with the first 20 patients undergoing curative-intent rectal cancer surgery at a single institution. Tech Coloproctol. 2014;18:473-80.

16. Heald RJ. A new solution to some old problems: transanal TME. Tech Coloproctol. 2013;17:257-8

17. McLemore EC, Coker AM, Devaraj B, et al. TAMIS-assisted laparoscopic low anterior resection with total mesorectal excision in a cadaveric series. Surg Endosc. 2013;27:3478-84.

18. Chen CC, Lai YL, Jiang JK, et al. The evolving practice of hybrid natural orifice transluminal endoscopic surgery (NOTES) for rectal cancer. Surg Endosc 2015:29:119-26.

\section{Publisher's Note}

Springer Nature remains neutral with regard to jurisdictional claims in published maps and institutional affiliations.
Ready to submit your research? Choose BMC and benefit from:

- fast, convenient online submission

- thorough peer review by experienced researchers in your field

- rapid publication on acceptance

- support for research data, including large and complex data types

- gold Open Access which fosters wider collaboration and increased citations

- maximum visibility for your research: over $100 \mathrm{M}$ website views per year

At BMC, research is always in progress.

Learn more biomedcentral.com/submissions 